\title{
NUMERICAL SIMULATION OF AIR FLOW IN A MODEL OF LUNGS WITH MOUTH CAVITY
}

\begin{abstract}
Jakub ELCNER, Frantisek LIZAL, Jan JEDELSKY, Miroslav JICHA
Abstract: The air flow in a realistic geometry of human lung is simulated with computational flow dynamics approach as stationary inspiration. Geometry used for the simulation includes oral cavity, larynx, trachea and bronchial tree up to the seventh generation of branching. Unsteady RANS approach was used for the air flow simulation. Velocities corresponding to 15,30 and 60 litres/min of flow rate were set as boundary conditions at the inlet to the model. These flow rates are frequently used as a representation of typical human activities. Character of air flow in the model for these different flow rates is discussed with respect to future investigation of particle deposition.
\end{abstract}

\section{INTRODUCTION}

If we want to deliver drugs into the bloodstream, we can use one of several ways how to ensure it. Most popular ways to drug delivery is per oral (Pill swallowing), intravenous (Drug injection to the vein) and inhalation (Breathing into lung). Drug inhalation represents a compromise between effective, but for most people feared intravenous method, and per oral method, which is not so efficient in delivering of all drugs into the bloodstream. This is caused by the fact that the blood is oxygenated right inside the lung by the inhaled air which can carry drugs. For the proper distribution to specific part of lung (oxidation take place in alveolar region, which begins approximately at twentieth generation of branching of bronchial tree [1]) it is necessary to know behaviour of air while flow through the respiratory tract. During the inspiration and respiration, the air flows through complicated system of branches and in every next generation changes its flow rate and velocity. These aspects affect the contour of flow fields which has influence on deposition of drug particles carried by the air. Flow fields can be investigated by In vivo, In vitro or In silico methods. In vivo methods cannot be used nowadays for ethical reasons and for its demanding measurements. In vitro methods, including for example High Resolution Computer Tomography (HRCT) [2], Laser Doppler Velocimetry (LDV) [3] or Phase Doppler Particle Anemometry (P/DPA) [4], are commonly used, but complicated geometry of bronchial tree make measuring in the highest generations of branching impossible. If we want to know the flow fields in these parts, the best way is CFD calculation. Another important factor which significantly influences the character of air flow in upper airways is model geometry. In the beginnings of research of airflow in human lung, the geometry will be replaced by the simplified system of cylindrical tubes, but studies shown that the realistic shape of geometry is necessary for accurate

\footnotetext{
- Jakub Elcner, Frantisek Lizal, Jan Jedelsky, PhD., Prof. Miroslav Jicha, CSc., Department of Thermodynamics and Environmental Engineering, Faculty of Mechanical Engineering, Brno University of Technology, Technicka 2896/2, 616 69, Brno, email: yelcne00@stud.fme.vutbr.cz
}

This is an Open Access article distributed under the terms of the Creative Commons Attribution License 2.0, which permits unrestricted use, distribution, and reproduction in any medium, provided the original work is properly cited. 
description of air flow field arrangment in respiratory tract. Thanks to the progress in radiology, we are able to obtain realistic geometry of whole respiratory tract and use it during the measurements and calculations.

\section{Methods}

\subsection{Model}

The model (Figure 1) used for numerical calculation of the airflow consists of mouth cavity, glottis, trachea and the model of bronchial tree up to seventh generation of branching. The model of mouth cavity was obtained from Lovelace Respiratory Research Institute in Albuquerque (USA) [5] as a wax model and it was digitized into stereolithographic format (.stl). The trachea was acquired from the Faculty Hospital St. Anna in Brno which employed computer tomography (CT) for the task. The bronchial tree model came from the institute of Anatomy and Cell Biology at the JustusLiebig University in Giessen (Germany) [6]. For the purposes of future comparison between numerical calculation and deposition measurement, the model was extended of mouth piece fitted on oral cavity and collectors at the end of bronchial tree which would be helpful for future research.

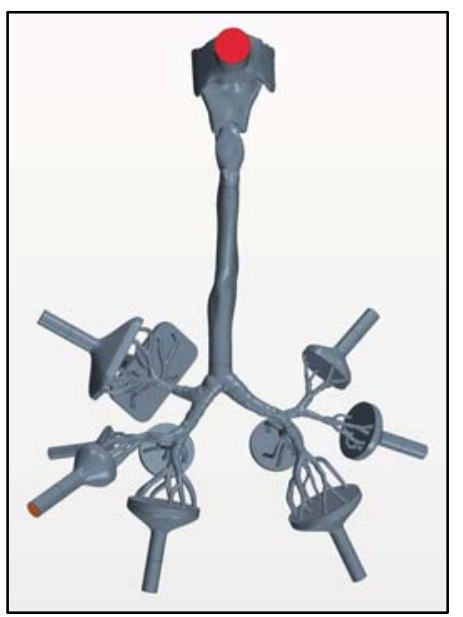

Figure 1: Model

\subsection{Numerical method}

Calculation was performed using StarCCM+ software. The model was placed in Cartesian coordinate system where the $Z$ axis was parallel to the axis of trachea and the $Y$ axis was in the direction of air entering to the mouth piece during the inspiration. The origin of the coordinate system was located at the inlet to the mouth nozzle to its axis.

The mesh contains approximately 2 million of polyhedral cells and it was built using generator integrated in StarCCM+. The core of polyhedral mesh was transformed into a prismatic layer of cells in the near wall region to improve the solution accuracy of the boundary layer.

Calculations were realized as inspiration, where air flows through model from mouth nozzle, over trachea and bronchial tree to collectors at the end of the bronchial tree. Three regimes with respect for comparison to other researches were investigated. Resting condition $(15 \mathrm{l} / \mathrm{min})$, normal breathing $(30 \mathrm{l} / \mathrm{min})$ and light activity $(60 \mathrm{l} / \mathrm{min})$. At the inlet to the mouth nozzle, the velocity boundary condition dependant on the regime was specified. Mouth nozzle diameter is $20 \mathrm{~mm}$, this means for $15 \mathrm{l} / \mathrm{min}$ that the Reynolds number on the inlet to the nozzle was $\mathrm{Re}=1054$ which corresponds to laminar flow. For 30 and $60 \mathrm{l} / \mathrm{min}$, the Reynolds numbers corresponds to transitional and turbulent flow therefore, the turbulent profile was specified as the field function at the inlet to the mouth nozzle. At the end of the collectors, the pressure outlet conditions were set. The simulation was run as a transient one with the use of the k-omega turbulence model. The results were considered converged when residuals dropped below $10^{-4}$ limit. This method was validated in [7].

\section{Results AND Discussion}

Comparison was performed on parts of the model which has significant influence on shape of air flow fields. At Figure $\mathbf{2}$ and $\mathbf{3}$ you can see velocity and turbulent kinetic energy (TKE) profiles on cross section through mouth cavity and trachea. On the Figure 2 you can see that the velocity at the inlet to the mouth nozzle respects the actual condition. For $15 \mathrm{l} / \mathrm{min}$, the laminar velocity profile is visible, but for 30 and $60 \mathrm{l} / \mathrm{min}$ the profile is turbulent. Shapes of velocity fields during the different volume 
flows are very similar, in the area of tongue, the streamlines going to compress and following the shape of tongue to the larynx area, where begins the phenomena called as laryngeal jet subscribed in [8]. While at the resting condition, the maximal velocity can be found in area of the first bifurcation, during the normal breathing and light activity, the maximal velocity lies at larynx and in the central part of trachea which can affect the deposition in these areas.

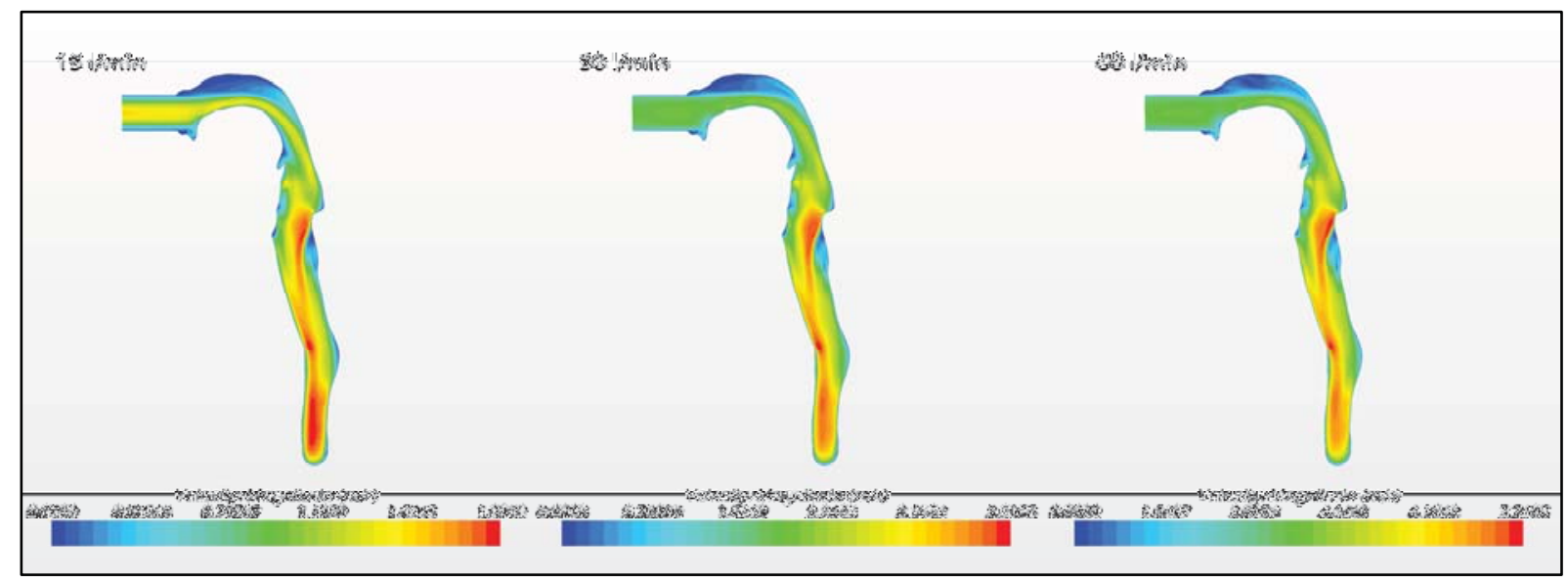

Figure 2: Mouth cavity and trachea, cross-section - Velocity

Profiles at Figure 3 show us small values of TKE during $15 \mathrm{l} / \mathrm{min}$ which respects the laminar character of flow at this flow rate. For highest flow rates we can observe creation of eddies in area under larynx which is probably caused by the laryngeal jet and by pressure differences below the stream of the air.

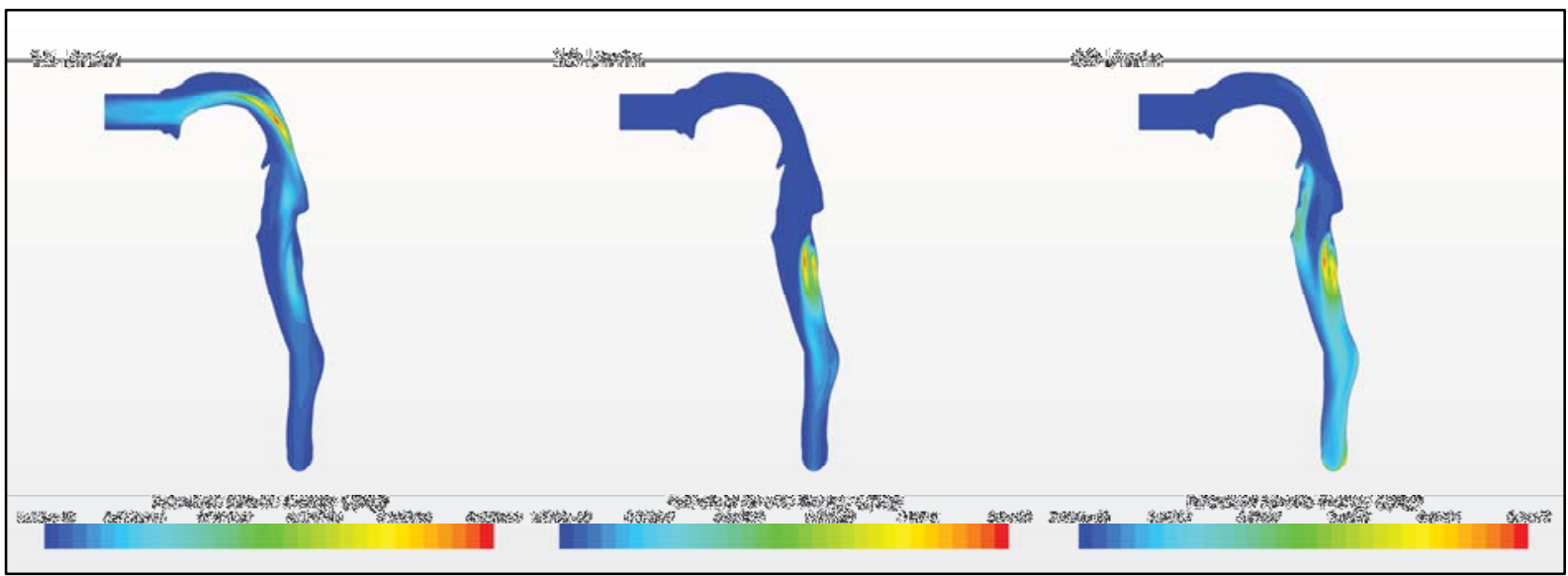

Figure 3: Mouth cavity and trachea, cross-section - TKE

Figures 5 and $\mathbf{6}$ shows the velocity and TKE layout in first bifurcation. Most important thing is distribution of air to left and right part of the bronchial tree. In the resting condition, the velocity profile before the bifurcation is almost symmetrical, but the highest flow rates, diversion of the profile to the right side of the model is visible (see Figure 4). This means that the highest values of flow rate can affect the flow distribution to other part of the lung. 


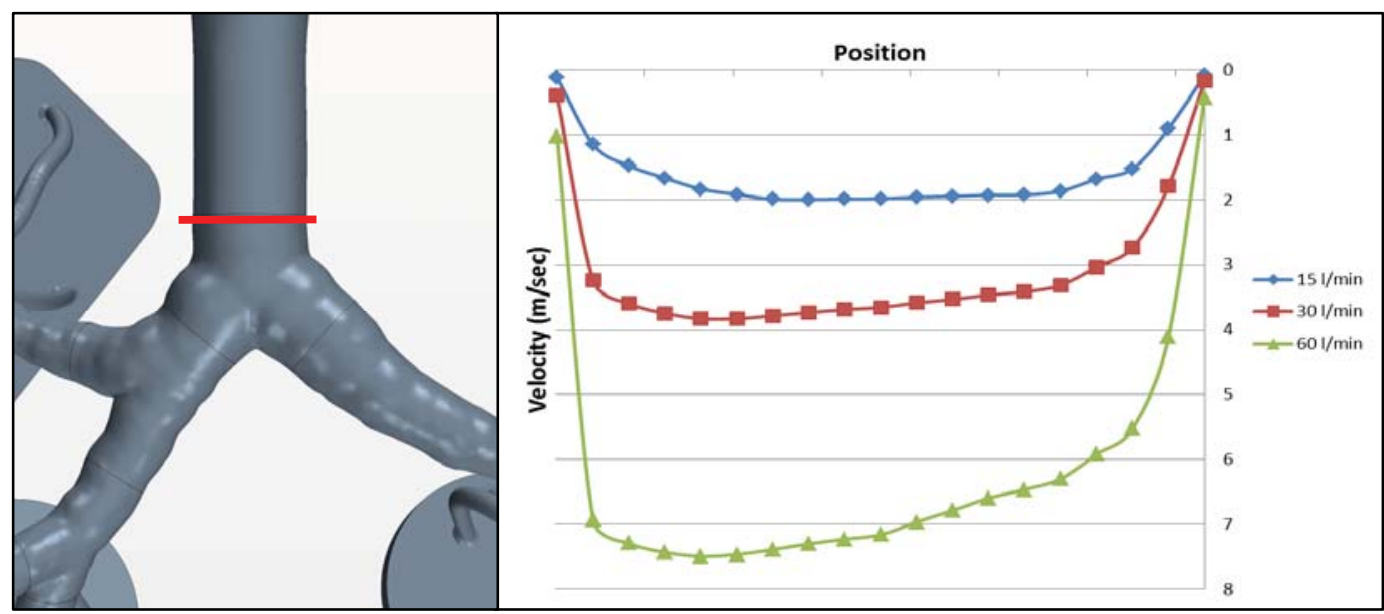

Figure 4: Velocity profile above 1st bifurcation

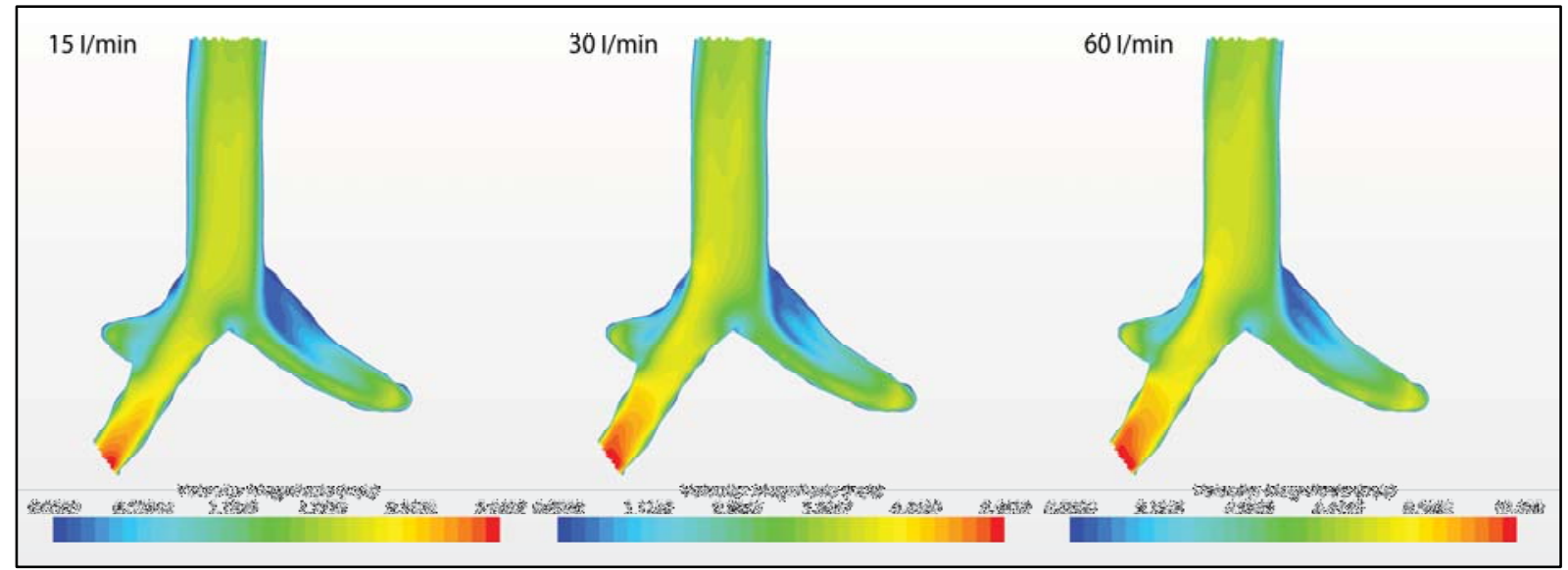

Figure 5: $1^{\text {st }}$ bifurcation, cross-section - Velocity

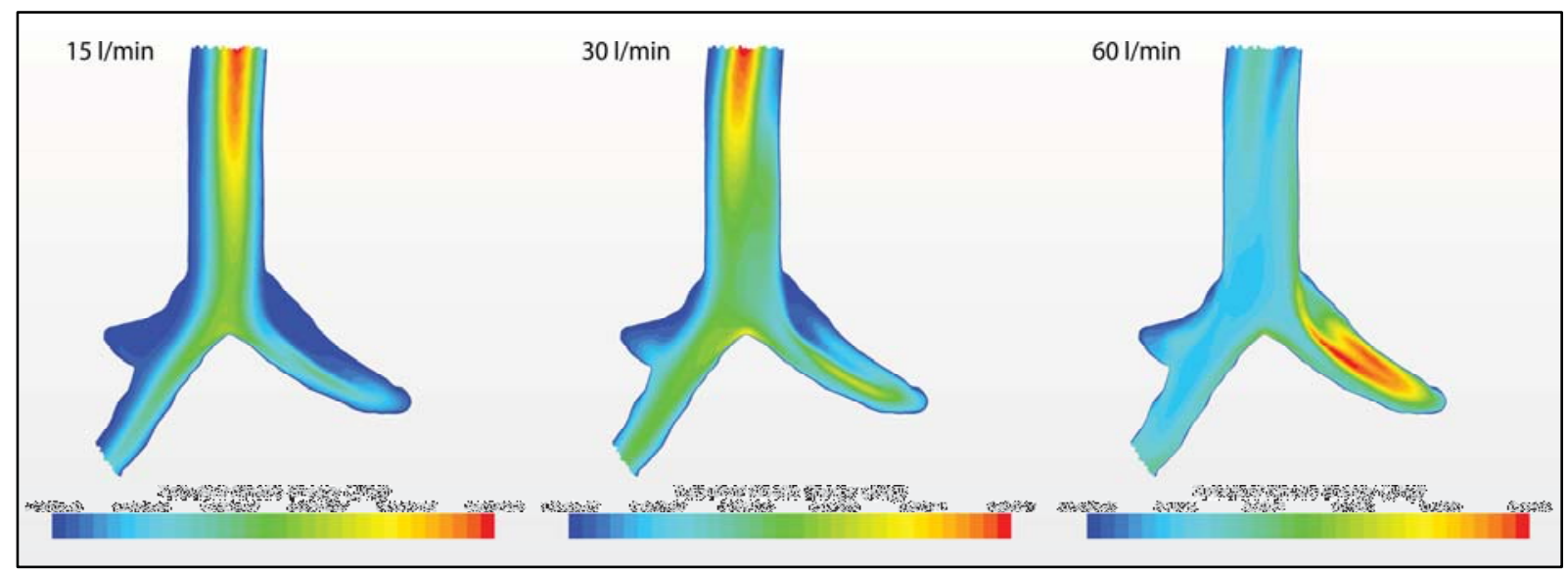

Figure 6: $1^{\text {st }}$ bifurcation, cross-section - TKE

\section{Conclusions}

Flow field calculations performed with the use of a realistic model of the upper respiratory tract is an important step in further research on the transport and deposition 
of aerosols in the respiratory tract of man. Future measurements and calculation based on knowledge in this paper can lead us to better understanding of drug delivery phenomena.

\section{ACKNOWLEDGMENTS}

This work was supported by the Czech grant agency under the grants GA101/09/H050 and project no. 105/11/1339, COST project OC10052 (COST Action Particles No. MP0806) funded by the Ministry of Education, Youth and Sports of the Czech Republic and also thanks to project FSI-S-11-6.

\section{REFERENCES}

[1] Weibel E. R.: Morphometry of the Human Lung, Springer Verlag and Academic Press, Berlin, New York, 1963.

[2] Tippe A., Perzl M., Li W., Schulz H.: Experimental analysis of flow calculations based on HRCT imaging of individual bifurcations, Respiration Physiology 117, 1999, 181-191

[3] Lieber B. B., Yao Z.: Oscillatory Flow in a Symmetric Bifurcation Airway Model, Annals of Biomedical Engineering Vol. 26, 1998, 821-830

[4] Jedelsky J., Lizal F., Jicha M.: Some aspects of particle motion under cyclic flow in realistic human airway model, The $21^{\text {st }}$ International Symposium on Transport Phenomena, 2010

[5] Zhou Y., Su W.-C., Cheng Y.S.: Fiber deposition in the tracheobronchial region: Experimental measurements, In Inhalation toxicology vol. 19, 2007, 1071-1078

[6] Schmidt A., Zidowitz S., Kriete A., Denhard T., Krass S., Peitgen H.-O.: A digital reference model of the human bronchial tree, Computerized Medical Imaging and Graphics vol. 27, 2004, 203-211

[7] Elcner J., Forman M., Jedelsky J., Lizal F., Jicha M.: Numerical simulation of air flow in a realistic model of the human upper airways, Experimental fluid mechanics, 2010

[8] Lin C.-L., Tawhai M.H., McLennan G., HOFFMAN E.A.: Characteristics of the turbulent laryngeal jet and its effect on airflow in the human intra-thoracic airways, Respiratory Physiology \& Neurobiology vol. 157, 2007, 295-309 